\title{
A 12-year follow-up study of all-cause and cardiovascular mortality among 10,532 people newly diagnosed with type 2 diabetes in Tayside, Scotland.
}

Karen N Barnett, Division of Clinical and Population Sciences and Education, Mackenzie Building, Kirsty Semple Way, University of Dundee, Dundee, DD2 4BF.

Research Student.

Simon A Ogston, Division of Clinical and Population Sciences and Education, Mackenzie Building, Kirsty Semple Way, University of Dundee, Dundee, DD2 4BF.

Lecturer in Statistics.

Marion ET McMurdo, Section of Ageing and Health, Division of Medicine and Therapeutics, University of Dundee, Dundee, DD1 9SY.

Professor of Ageing and Health.

Andrew D Morris, Diabetes Research Centre, University of Dundee, Dundee, DD1 9SY. Professor of Diabetic Medicine and Consultant Physician.

Josie MM Evans, Department of Nursing and Midwifery, University of Stirling, Stirling, FK9 4LA.

Lecturer in Public Health.

Corresponding author:

Dr Josie Evans

Department of Nursing and Midwifery

University of Stirling

Stirling

FK9 4LA

Tel no: +44 1786466352

Fax no: +44 1786466333

E mail: josie.evans@stir.ac.uk

Running title: Mortality and type 2 diabetes

Main text word count: 2,499

Abstract word count: 246

No of Tables: 2

No of Figures: 3 


\begin{abstract}
Aim: To determine absolute and relative risks of all-cause and cardiovascular mortality among patients newly diagnosed with type 2 diabetes. Methods: In an observational cohort study using record-linkage databases, based in Tayside, Scotland, UK, we identified newly diagnosed patients with type 2 diabetes in 1993-2004. We also identified a set of nondiabetic comparators from lists of patients registered with General Practice, individually matched to the diabetic patients by sex, age and deprivation. We followed up patients for mortality and cardiovascular mortality over a 12 year period, and calculated hazard ratios (HRs) using Cox regression. Results: There were 10,532 patients with type 2 diabetes, and 21,056 non-diabetic comparators. Diabetic patients in every age/sex group had higher absolute mortality rates. Even taking deprivation into account, the HR for mortality was 1.32 (95\% CI 1.25 to 1.40$)$, decreasing to 1.15 (1.09 to 1.22 ) after adjusting for pre-existing cardiovascular disease. The HRs for cardiovascular mortality were higher, decreasing from 1.51 (1.37 to 1.67$)$ to 1.23 (1.11 to 1.36$)$ after adjusting for pre-existing cardiovascular disease. The HRs decreased with increasing age at diagnosis, although the difference in absolute rate of mortality increased slightly with age. Increased mortality risks were only evident two years after diagnosis and increased thereafter. Conclusions: Patients with type 2 diabetes have an increased risk of all-cause and cardiovascular mortality compared with non diabetic comparators, although this is not observable immediately after diagnosis. Age at diagnosis and duration of the disease independently affect absolute and relative mortality risk.
\end{abstract}




\section{Introduction}

Numerous studies have shown that type 2 diabetes reduces life expectancy ${ }^{1-4}$ mainly due to an increased risk of cardiovascular mortality ${ }^{3}$. Studies have suggested that patients with type 2 diabetes may have up to a three-fold increase in mortality compared with people without diabetes $^{3,4}$. However, many studies that have investigated mortality have taken a crosssectional sample of patients with type 2 diabetes at one point in time and followed them up for mortality. The published risks then represent the mean increased risks across heterogeneous groups of patients with varying disease duration and age of diagnosis. The increased mortality risk among patients newly diagnosed with type 2 diabetes is not well documented. The few studies that have followed patients from diagnosis suggest that the relative risk of mortality associated with diabetes decreases with increasing age at diagnosis ${ }^{5-}$ 8

Published literature on cardiovascular mortality in newly diagnosed patients with type 2 diabetes is even less well documented, although a recent American study showed more than a two-fold increase in cardiovascular mortality in newly diagnosed older patients ${ }^{9}$. This study also found mortality risk to rise only two years after diagnosis and not increase thereafter, a finding that conflicts with studies that suggest that mortality rises with increasing duration of diabetes, independent of cardiovascular risk factors ${ }^{10,11}$.

We used a diabetic clinical information system to follow up 10,532 patients newly diagnosed with type 2 diabetes in Tayside, Scotland and to evaluate the mortality risks associated with 
type 2 diabetes. We also investigated how age at diagnosis and disease duration affect allcause and cardiovascular mortality. 


\section{Methods}

This observational cohort study was carried out among the resident population of Tayside Health Board, Scotland (approx. 400,000 people). Data were provided by the Health Informatics Centre (HIC), University of Dundee, which has developed the record-linkage of multiple, routinely collected datasets to carry out anonymised health related research in Tayside. Electronic linkage is facilitated by the widespread use of a nine digit Community Health Identifier (CHI) that is assigned to all patients in Scotland registered with a General Practitioner. Datasets used for this study include the SCI-DC diabetes clinical information system (formerly known as DARTS) ${ }^{12}$, computerised death certification records from the Registrar General with ICD9/ICD10-coded causes of death ${ }^{13,14}$, and Scottish Morbidity Records of inpatient hospital activity ${ }^{15}$. All HIC data are anonymised prior to analysis to maintain confidentiality and to conform to Data Protection legislation.

SCI-DC/DARTS is a validated population-based diabetes clinical information system. The original DARTS database for Tayside has $95 \%$ sensitivity at identifying people with diabetes ${ }^{12}$. The register was used to identify all patients newly diagnosed with type 2 diabetes in Tayside between January 1993 and December 2004. All patients who are diagnosed with diabetes aged 35 years or over are classified as having type 2 diabetes, as are those who are diagnosed when younger but with no requirement for insulin. However, because misclassification of diabetes type is common in younger age groups we restricted this study to patients over the age of 35 years. We also excluded patients whose date of diagnosis was unknown or who left Tayside within the study period. 
A non diabetic comparator cohort was generated at random from the community-based electronic lists of people registered with General Practitioners in Tayside. Two non-diabetic people were matched to every patient with type 2 diabetes for sex and age (within 1 year). Postal sectors in Scotland are assigned an area-based measure of material deprivation, known as the Carstairs score ${ }^{16}$. Comparators were therefore identified from the same postal sectors as the diabetic patients to take account of possible differences in deprivation related to geographical area. However, where this was not possible, a match was made on GP practice. The index date of a patient with diabetes was their date of diagnosis; also used as the index date for matched comparators (who had to be alive on this date). Patients were followed up for a maximum of 12 years for mortality, to an end-date of $9^{\text {th }}$ February 2005 (the last date for which dates of death were available). The underlying cause of death was ascertained from death certificate records.

Information on whether patients had been hospitalized with any ICD9/10 diagnosis code for cardiovascular disease at any time from 1980 onwards was obtained from the Scottish Morbidity Record 1 (SMR01) to identify those with pre-existing cardiovascular disease (ICD9 codes 410-414, 428-438, 518.4, 786.5 and corresponding ICD10 codes). SMR01 holds information on all hospital admissions in Scotland from 1980.

We obtained the numbers of deaths for diabetic patients and non-diabetic comparators, stratified by sex and age at diagnosis. Cardiovascular deaths were identified as those that had a cardiovascular code for the underlying cause of death on the death certificate (codes defined above). We calculated absolute rates of all-cause and cardiovascular mortality by 
dividing the total numbers of deaths in each age/sex group by the total number of days follow up (to the end of the study or to a participant's date of death). A Kaplan-Meier survival curve was constructed for diabetic and non-diabetic comparators and a Cox regression survival analysis was used to calculate unadjusted hazard ratios (HRs) for all-cause and cardiovascular mortality. Because not all patients were matched for postal sector, we adjusted the HRs for deprivation using the Carstairs score. Previous cardiovascular admission was also treated as a covariate. Because cause of death information was judged to be reliable only up to $9^{\text {th }}$ December 2004 , note that this was the end-date for all analyses of cardiovascular mortality.

To examine differences in mortality risk associated with new-onset diabetes over follow up, adjusted HRs were calculated for six follow up intervals, 0-2, 2-4, 4-6, 6-8 and 10-12 years for both all-cause mortality and cardiovascular mortality.

This study was granted ethical approval by the Tayside Committee for Medical Research Ethics. 


\section{Results}

There were 10,532 people ( $52.3 \%$ male) over the age of 35 years who were diagnosed with type 2 diabetes between 1993 and 2004; there were 21,056 non-diabetic comparators. The majority were matched by postal sector. $2,334(22.2 \%)$ of the patients with diabetes had a previous hospital admission for cardiovascular disease, compared with 2,626 (12.5\%) of the non-diabetic comparators. During a maximum follow-up period of 12 years, 1,863 (17.7\%) patients with diabetes and 2,962 (14.1\%) non-diabetic comparators died. The main causes of death were diseases of the circulatory system $(44.9 \%, 39.3 \%)$ and neoplasms $(25.3 \%$, $27.7 \%$ ), for diabetic and non diabetic comparators respectively. Table 1 presents the numbers of deaths for all-cause and cardiovascular mortality by age groups for men and women respectively. The absolute rates per 1,000 patient years are also shown in Table 1 and Figs 1 and 2 .

The higher absolute rates of all-cause mortality and cardiovascular mortality are clearly evident for patients with diabetes. All rates were higher for males, except the all-cause mortality rate among diabetic patients over 75 years. The difference in absolute rates of allcause mortality appeared to widen slightly among females and narrow slightly among males, as age increased. It is also notable that the widening of the absolute rates of cardiovascular mortality between diabetic patients and non-diabetic comparators appeared to occur slightly earlier among women than men.

A Cox regression survival analysis (adjusted for deprivation) showed that patients with type 2 diabetes had an increased HR (with 95\% confidence intervals) of 1.32 (1.25 to 1.40) for 
mortality compared with non diabetic comparators, after adjusting for differences in deprivation between the groups (Table 2). However, after adjusting for previous cardiovascular admission, the risk reduced to 1.15 (1.09 to 1.22$)$. The risks were very similar for men and women. The same patterns were observed for cardiovascular mortality, although the HRs were slightly higher. The HRs for all-cause and cardiovascular mortality decreased with increasing age at diagnosis. In the age group 45-54 years, much higher HRs were observed among women compared to men, particularly for cardiovascular mortality.

Fig 3 presents the overall HRs for all-cause and cardiovascular mortality, stratified by number of years follow up (duration of diabetes). Although the confidence intervals are fairly wide, there seems to be a trend for increasing risk of all-cause mortality with increasing duration of diabetes, reaching a peak between 6 and 8 years, and then decreasing. This trend is even more marked for cardiovascular mortality, but reaching a peak slightly earlier. 


\section{Conclusions}

This study further supports the literature showing that type 2 diabetes reduces life expectancy $^{1-4}$. In general, patients with diabetes had higher absolute rates of all-cause and cardiovascular mortality than non-diabetic comparators, even when they were matched for deprivation levels (deprivation being an important confounder because deprived people are more likely to have diabetes ${ }^{17}$, and to have higher rates of mortality ${ }^{18}$ ). Even after adjusting more fully for deprivation and for previous cardiovascular disease, increased risks of allcause and cardiovascular mortality associated with type 2 diabetes were still apparent. These risks were much lower than those reported in cross-sectional studies ${ }^{3,4}$, not only because we adjusted for deprivation, but probably also because our longitudinal design among a clearly defined cohort of newly diagnosed patients, provides a more accurate estimate of risk.

In general, the differences in absolute rate between diabetic patients and their comparators widened slightly as age at diagnosis increased. Despite this, the hazard ratios decreased with increasing age of diagnosis. No increased risk associated with type 2 diabetes was observed among very old men (over the age of 75 years), as has been observed previously ${ }^{5}$. This is also consistent with a diminishing reduction in life expectancy identified among patients with increasing age of diagnosis in a cross-sectional sample ${ }^{19}$. However, this result is slightly misleading in that the increased risk associated with diabetes is deemed to be low (as defined by the hazard ratio) when compared with a very high background mortality rate (among older people) and is deemed to be high when compared with a low background mortality rate (among younger people). While a young person diagnosed with type 2 diabetes has a very high HR for all-cause mortality, their absolute rate is still relatively low because the 
background rate is low. The converse applies to older people. The HR is relatively low but diabetes is still associated with a large number of deaths because the background rate is high. It is therefore important that clinicians understand and are able to communicate measures of risk appropriately ${ }^{20}$.

Similar patterns were observed for cardiovascular mortality. The risks observed were lower than those found in other studies ${ }^{9}$, perhaps because we matched and further adjusted for deprivation. The effect of pre-existing cardiovascular disease on the risk of all-cause and cardiovascular mortality is also clearly shown, with HRs decreasing substantially after adjusting for this covariate, particularly for cardiovascular mortality (as might be expected). There were no data available for classic cardiovascular risk factors (BMI, blood pressure, serum lipids, smking) so it was not possible to determine to what extent this increased cardiovascular risk could be explained by these factors. Also, we may not have fully adjusted for pre-existing cardiovascular disease for those patients who had never been hospitalized. However, this effect is likely to be small.

This study provides further evidence that diabetes confers a greater increased risk of cardiovascular mortality among younger women (aged 45-64 years) compared with men of the same age. This has been observed in other studies ${ }^{21,22}$, and more adverse cardiovascular risk profiles among women, but more aggressive treatment for men, has been one explanation for the difference. However, a meta-analysis found no difference between men and women after adjusting for cardiovascular risk factors ${ }^{23}$. We still found high risks of cardiovascular mortality among younger women even after adjusting for previous 
cardiovascular disease (but not other cardiovascular risk factors). Nevertheless, although in general men have higher cardiovascular mortality rates and the actual numbers of deaths associated with diabetes are higher in men than women ${ }^{23}$, the impact of diabetes on mortality risk in younger women should not be under-estimated.

In this study, we identified almost no adverse effect on all-cause or cardiovascular mortality during the first two years after diagnosis with diabetes (after adjusting for previous cardiovascular risk), but then a trend for increased risk with increasing duration. This declined after about eight years. Our results are therefore compatible with the hypothesis that long-term hyperglycaemia leads to atherosclerosis, and that the detrimental effects on mortality are not immediately evident after diagnosis, especially given that many people have diabetes undetected for a number of years before clinical diagnosis ${ }^{24}$. In contrast, a study from the US suggested that increased risk of all-cause and cardiovascular mortality was elevated immediately after diagnosis and did not appear to increase with time ${ }^{9}$. Note though that this US study was among only 282 older patients (over 65 years) and the confidence intervals were wide. A UK study found an increased risk of mortality during the first five years after diagnosis, but did not break down the risks within this period ${ }^{25}$. However, neither study adjusted for pre-existing cardiovascular disease.

We are confident that the data used have produced an accurate measure of the effect of type 2 diabetes on mortality risk. The DARTS clinical information system has high sensitivity at identifying patients with diabetes. Ascertainment of mortality relied on a validated national dataset. The underlying causes of death recorded are as stated on a patient's death certificate, 
so while some may have been coded incorrectly, we have probably identified most cardiovascular deaths. We used hospital admission as a proxy for pre-existing cardiovascular disease so this could have been under-estimated. However, this limitation probably applies equally to diabetic patients and comparators. In summary, we have provided a detailed analysis of all-cause and cardiovascular mortality risks among a large cohort of patients newly diagnosed with type 2 diabetes in Scotland. 


\section{Acknowledgements}

We thank Chief Scientist Office, Scotland, for funding a $\mathrm{PhD}$ research studentship (CZS/1/35). The researchers were independent from the funding body. We also thank the staff of the Health Informatics Centre who provided data. 
Tables

\begin{tabular}{|c|c|c|c|c|}
\hline \multicolumn{5}{|c|}{ MALES } \\
\hline \multicolumn{5}{|c|}{ All-cause mortality } \\
\hline & \multicolumn{2}{|c|}{ Diabetic patients } & \multicolumn{2}{|c|}{ Non-diabetic comparators } \\
\hline & $\begin{array}{c}\text { Total } \\
\text { (no. of deaths) }\end{array}$ & $\begin{array}{c}\text { Absolute rate } \\
\text { per } 1,000 \text { pat yrs } \\
(95 \% \mathrm{Cl})\end{array}$ & $\begin{array}{c}\text { Total } \\
\text { (no. of deaths) }\end{array}$ & $\begin{array}{c}\text { Absolute rate } \\
\text { per } 1,000 \text { pat yrs } \\
(95 \% \mathrm{Cl})\end{array}$ \\
\hline $35-44$ & $419(11)$ & $5.60(2.29-8.90)$ & $836(5)$ & $1.25(0.15-2.35)$ \\
\hline $45-54$ & $1052(62)$ & $12.84(9.65-16.04)$ & $2105(61)$ & $6.13(4.59-7.67)$ \\
\hline $55-64$ & $1557(198)$ & $28.61(24.62-32.59)$ & $3118(271)$ & $18.87(16.62-21.11)$ \\
\hline $65-74$ & $1594(371)$ & $56.53(50.78-62.29)$ & $3178(595)$ & $43.38(39.90-46.87)$ \\
\hline $75+$ & $884(341)$ & $113.68(101.61-125.74)$ & $1774(646)$ & $104.80(96.72-112.88)$ \\
\hline All ages & $5506(983)$ & $42.23(39.59-44.87)$ & $11,011(1578)$ & $32.75(31.13-34.36)$ \\
\hline \multicolumn{5}{|c|}{ Cardiovascular mortality } \\
\hline & \multicolumn{2}{|c|}{ Diabetic patients } & \multicolumn{2}{|c|}{ Non-diabetic comparators } \\
\hline & $\begin{array}{c}\text { Total } \\
\text { (no. of deaths) }\end{array}$ & $\begin{array}{c}\text { Absolute rate } \\
\text { per } 1,000 \text { pat yrs } \\
(95 \% \mathrm{Cl})\end{array}$ & $\begin{array}{c}\text { Total } \\
\text { (no. of deaths) }\end{array}$ & $\begin{array}{c}\text { Absolute rate } \\
\text { per } 1,000 \text { pat yrs } \\
(95 \% \mathrm{Cl})\end{array}$ \\
\hline $35-44$ & $411(7)$ & $3.69(0.96-6.42)$ & $821(1)$ & $0.26(-0.25-0.77)$ \\
\hline $45-54$ & $1034(13)$ & $2.79(1.27-4.30)$ & $2063(11)$ & $1.15(0.47-1.82)$ \\
\hline $55-64$ & $1522(66)$ & $9.86(7.48-12.24)$ & $3057(80)$ & $5.76(4.50-7.02)$ \\
\hline $65-74$ & $1572(141)$ & $22.19(18.52-25.85)$ & $3130(193)$ & $14.53(12.48-16.58)$ \\
\hline $75+$ & $872(143)$ & $49.18(41.12-57.24)$ & $1750(216)$ & $36.16(31.34-40.98)$ \\
\hline All ages & $5411(370)$ & $16.43(14.76-18.11)$ & $10,821(501)$ & $10.75(9.81-11.69)$ \\
\hline \multicolumn{5}{|c|}{ FEMALES } \\
\hline \multicolumn{5}{|c|}{ All-cause mortality } \\
\hline & \multicolumn{2}{|c|}{ Diabetic patients } & \multicolumn{2}{|c|}{ Non-diabetic comparators } \\
\hline & $\begin{array}{c}\text { Total } \\
\text { (no. of deaths) }\end{array}$ & $\begin{array}{c}\text { Absolute rate } \\
\text { per } 1,000 \text { pat yrs } \\
(95 \% \mathrm{Cl})\end{array}$ & $\begin{array}{c}\text { Total } \\
\text { (no. of deaths) }\end{array}$ & $\begin{array}{c}\text { Absolute rate } \\
\text { per } 1,000 \text { pat yrs } \\
(95 \% \mathrm{Cl})\end{array}$ \\
\hline $35-44$ & $328(10)$ & $6.40(2.43-10.36)$ & $638(4)$ & $1.31(0.03-2.60)$ \\
\hline $45-54$ & $749(38)$ & $11.24(7.67-14.82)$ & $1512(24)$ & $3.36(2.01-4.70)$ \\
\hline $55-64$ & $1233(123)$ & $20.85(17.17-24.54)$ & $2452(149)$ & $12.37(10.38-14.35)$ \\
\hline $65-74$ & $1506(255)$ & $40.55(35.58-45.53)$ & $3032(408)$ & $30.81(27.82-33.80)$ \\
\hline $75+$ & $1210(454)$ & $113.92(103.44-124.40)$ & $2411(799)$ & $91.14(84.82-97.46)$ \\
\hline $\mathrm{Al}$ ages & $5026(880)$ & $41.68(38.92-44.43)$ & $10,045(1384)$ & $31.27(29.63-32.92)$ \\
\hline \multicolumn{5}{|c|}{ Cardiovascular mortality } \\
\hline & \multicolumn{2}{|c|}{ Diabetic patients } & \multicolumn{2}{|c|}{ Non-diabetic comparators } \\
\hline & $\begin{array}{c}\text { Total } \\
\text { (no. of deaths) }\end{array}$ & $\begin{array}{c}\text { Absolute rate } \\
\text { per } 1,000 \text { pat yrs } \\
(95 \% \mathrm{Cl})\end{array}$ & $\begin{array}{c}\text { Total } \\
\text { (no. of deaths) }\end{array}$ & $\begin{array}{c}\text { Absolute rate } \\
\text { per } 1,000 \text { pat yrs } \\
(95 \% \mathrm{Cl})\end{array}$ \\
\hline $35-44$ & $321(2)$ & $1.32(-0.51-3.16)$ & $624(1)$ & $0.34(-0.33-1.01)$ \\
\hline $45-54$ & $733(9)$ & $2.76(0.96-4.56)$ & $1482(3)$ & $0.43(-0.06-0.93)$ \\
\hline $55-64$ & $1215(42)$ & $7.35(5.13-9.58)$ & $2414(27)$ & $2.32(1.44-3.19)$ \\
\hline $65-74$ & $1485(97)$ & $15.96(12.79-19.14)$ & $2989(125)$ & $9.77(8.05-11.48)$ \\
\hline $75+$ & $1182(165)$ & $42.76(36.24-49.29)$ & $2356(297)$ & $34.96(30.98-38.93)$ \\
\hline All ages & $4936(315)$ & $15.43(13.72-17.13)$ & $9865(453)$ & $10.59(9.61-11.56)$ \\
\hline
\end{tabular}

Table 1: Total numbers of deaths and absolute rates of mortality and cardiovascular mortality (with $95 \%$ CI) for patients with type 2 diabetes and non diabetic comparators, stratified by age and sex 


\begin{tabular}{|c|c|c|c|c|}
\hline & \multicolumn{2}{|c|}{ All-cause mortality } & \multicolumn{2}{|c|}{ Cardiovascular mortality } \\
\hline & $\begin{array}{l}\mathrm{HR}(95 \% \mathrm{Cl})- \\
\text { adjusted for } \\
\text { deprivation only }\end{array}$ & $\begin{array}{l}\mathrm{HR}(95 \% \mathrm{Cl}) \text { - adjusted } \\
\text { for deprivation and } \\
\text { previous cardiovascular } \\
\text { disease }\end{array}$ & $\begin{array}{l}\mathrm{HR}(95 \% \mathrm{Cl})-\text { adjusted } \\
\text { for deprivation only }\end{array}$ & $\begin{array}{l}\mathrm{HR}(95 \% \mathrm{Cl}) \text { - adjusted } \\
\text { for deprivation and } \\
\text { previous cardiovascular } \\
\text { disease }\end{array}$ \\
\hline \multicolumn{5}{|l|}{ Men } \\
\hline $35-44$ & $4.59(1.59-13.28)$ & $4.17(1.41-12.35)$ & $15.91(1.94-130.16)$ & $14.74(1.77-122.69)$ \\
\hline $45-54$ & $2.19(1.53-3.13)$ & $2.01(1.39-2.91)$ & $2.44(1.09-5.46)$ & $1.95(0.84-4.52)$ \\
\hline $55-64$ & $1.52(1.27-1.83)$ & $1.36(1.13-1.64)$ & $1.73(1.25-2.40)$ & $1.33(0.95-1.86)$ \\
\hline $65-74$ & $1.33(1.17-1.52)$ & $1.22(1.07-1.39)$ & $1.57(1.26-1.95)$ & $1.36(1.09-1.70)$ \\
\hline $75+$ & $1.11(0.97-1.26)$ & $1.06(0.92-1.20)$ & $1.40(1.14-1.74)$ & $1.29(1.04-1.60)$ \\
\hline All Ages (35+) & $1.30(1.20-1.41)$ & $1.14(1.05-1.24)$ & $1.55(1.36-1.78)$ & $1.26(1.10-1.45)$ \\
\hline \multicolumn{5}{|l|}{ Women } \\
\hline $35-44$ & $4.38(1.36-14.08)$ & $3.90(1.20-12.65)$ & $3.59(0.32-40.71)$ & $2.15(0.16-28.12)$ \\
\hline $45-54$ & $3.20(1.90-5.36)$ & $2.67(1.57-4.56)$ & $6.43(1.73-23.87)$ & $4.97(1.29-19.15)$ \\
\hline $55-64$ & $1.69(1.32-2.14)$ & $1.51(1.18-1.93)$ & $3.16(1.94-5.13)$ & $2.71(1.65-4.46)$ \\
\hline $65-74$ & $1.32(1.13-1.54)$ & $1.17(1.00-1.37)$ & $1.63(1.25-2.13)$ & $1.34(1.02-1.76)$ \\
\hline $75+$ & $1.29(1.15-1.45)$ & $1.20(1.07-1.35)$ & $1.26(1.04-1.52)$ & $1.13(0.93-1.37)$ \\
\hline All Ages (35+) & $1.34(1.23-1.46)$ & $1.16(1.07-1.27)$ & $1.47(1.27-1.69)$ & $1.19(1.03-1.38)$ \\
\hline \multicolumn{5}{|l|}{ All } \\
\hline $35-44$ & 4.46 (2.03-9.78) & $3.98(1.79-8.86)$ & $9.32(2.00-43.54)$ & $7.92(1.65-37.91)$ \\
\hline $45-54$ & $2.52(1.89-3.38)$ & $2.26(1.68-3.05)$ & $3.31(1.69-6.47)$ & $2.62(1.31-5.27)$ \\
\hline $55-64$ & $1.57(1.36-1.82)$ & $1.39(1.20-1.62)$ & $2.09(1.60-2.74)$ & $1.64(1.25-2.17)$ \\
\hline $65-74$ & $1.32(1.20-1.46)$ & $1.19(1.08-1.32)$ & $1.59(1.34-1.88)$ & $1.35(1.13-1.60)$ \\
\hline $75+$ & $1.21(1.11-1.32)$ & $1.13(1.04-1.24)$ & $1.32(1.15-1.52)$ & $1.20(1.04-1.38)$ \\
\hline All Ages (35+) & $1.32(1.25-1.40)$ & $1.15(1.09-1.22)$ & $1.51(1.37-1.67)$ & $1.23(1.11-1.36)$ \\
\hline
\end{tabular}

Table 2: Hazard ratios for risks of mortality and cardiovascular mortality among patients with type 2 diabetes compared to non-diabetic comparators, stratified by age and sex. 


\section{Figures}

Fig 1

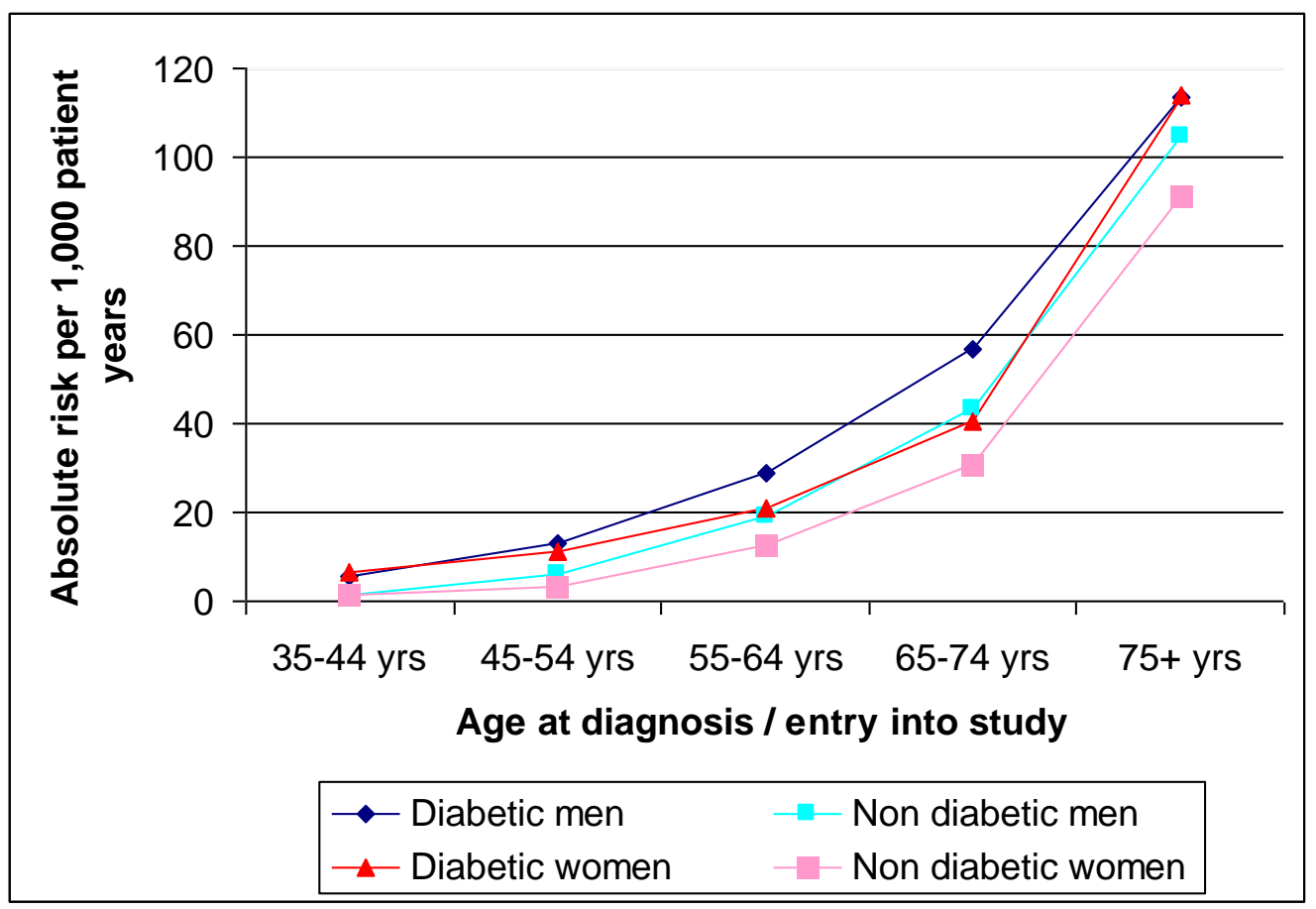


Fig 2

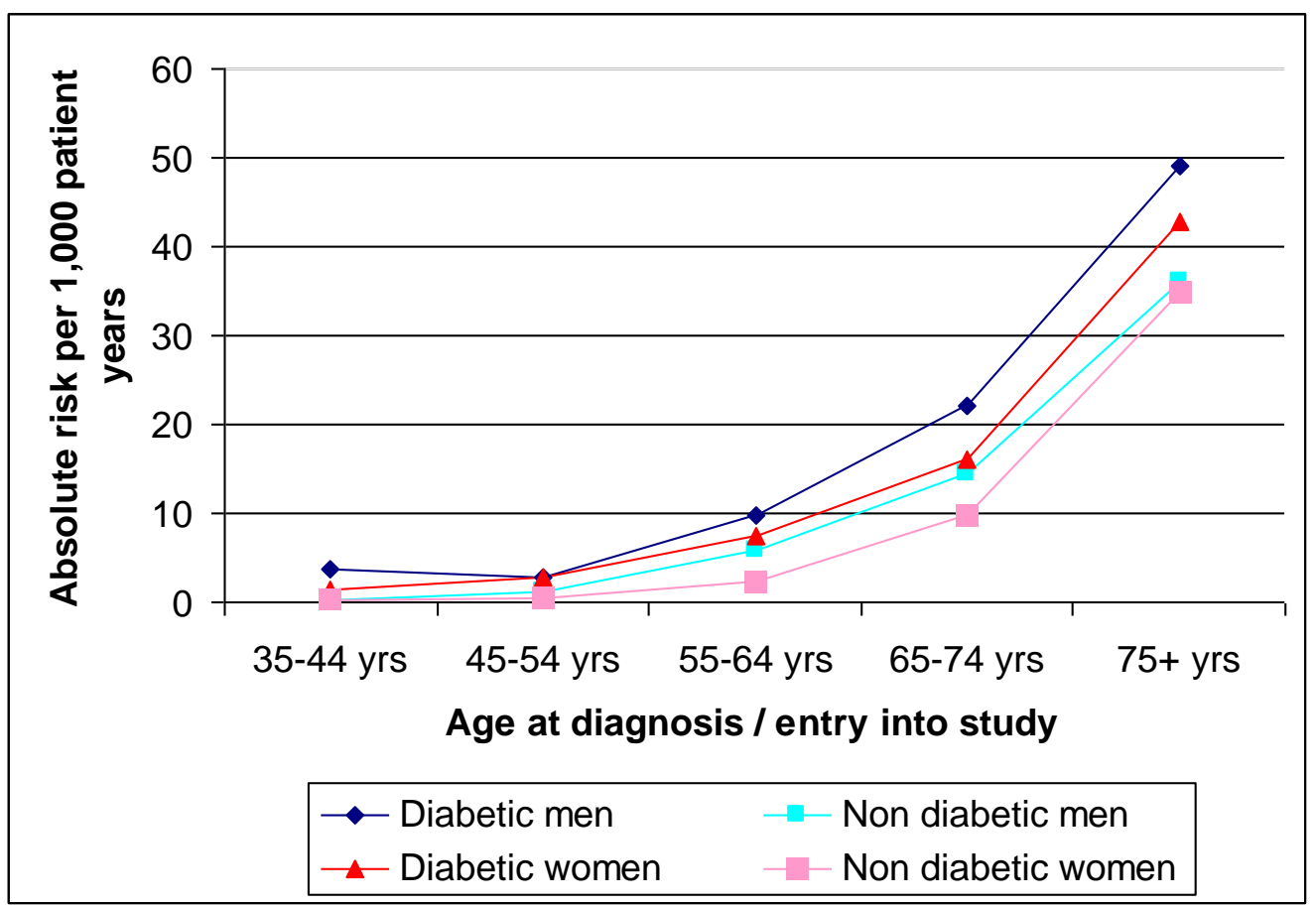


Fig 3

Hazard ratios (with $95 \% \mathrm{Cl}$ )

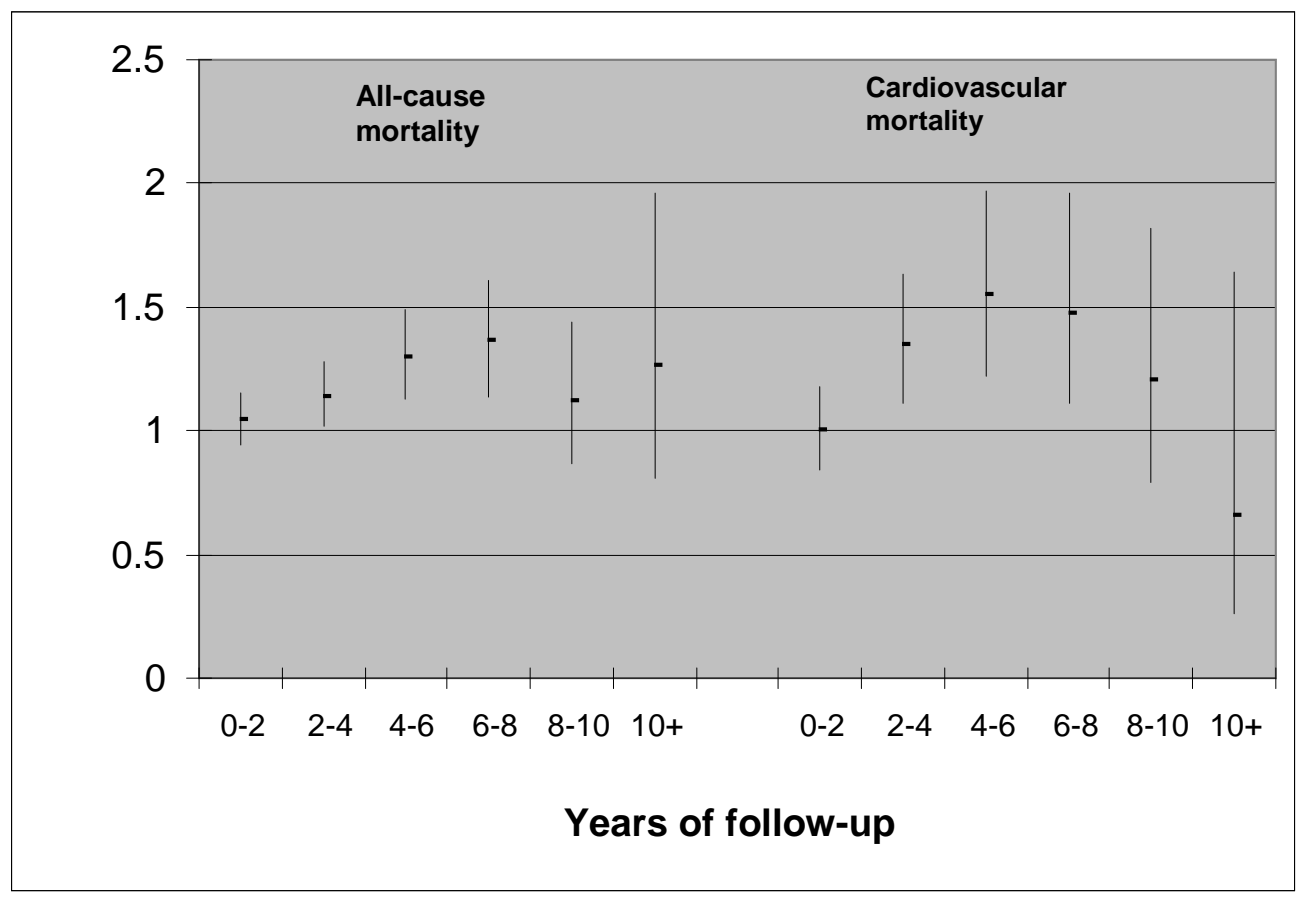




\section{Legend to Figures}

Figure 1: Absolute rates of all-cause mortality among newly diagnosed patients with type 2 diabetes and non-diabetic comparators.

Figure 2: Absolute rates of cardiovascular mortality among newly diagnosed patients with type 2 diabetes and non-diabetic comparators.

Figure 3: Hazard ratios, adjusted for deprivation and previous cardiovascular admission, for all-cause and cardiovascular mortality among patients with diabetes compared to nondiabetic comparators, stratified by length of follow-up (duration of diabetes). 
Declaration of Competing Interests

No Competing Interests to declare. 


\section{References}

1. Mulnier HE, Seaman HE, Raleigh VS, Soedamah-Muthu SS, Colhoun HM, Lawrenson RA. Mortality in people with type 2 diabetes in the UK. Diabetic Medicine 2006;23(5):516-521.

2. Almdal T, Scharling H, Jensen JS, Vestergaard H. The independent effect of type 2 diabetes mellitus on ischemic heart disease, stroke, and death: a population-based study of 13,000 men and women with 20 years of follow-up. Archives of Internal Medicine 2004;164(13):1422-6.

3. Salles GF, Bloch KV, Cardoso CR. Mortality and predictors of mortality in a cohort of Brazilian type 2 diabetic patients. Diabetes Care 2004;27(6):1299-305.

4. Hu FB, Stampfer MJ, Solomon CG, Liu S, Willett WC, Speizer FE, et al. The impact of diabetes mellitus on mortality from all causes and coronary heart disease in women: 20 years of follow-up. Archives of Internal Medicine 2001;161(14):1717-23.

5. Tan HH, McAlpine RR, James P, Thompson P, McMurdo ME, Morris AD, et al. Diagnosis of type 2 diabetes at an older age: effect on mortality in men and women. Diabetes Care 2004;27(12):2797-9.

6. Kuller LH, Velentgas P, Barzilay J, Beauchamp NJ, O'Leary DH, Savage PJ. Diabetes mellitus: subclinical cardiovascular disease and risk of incident cardiovascular disease and all-cause mortality. Arteriosclerosis, Thrombosis \& Vascular Biology. 2000;20(3):823-9.

7. Muggeo M, Verlato G, Bonora E, Bressan F, Girotto S, Corbellini M, et al. The Verona diabetes study: a population-based survey on known diabetes mellitus prevalence and 5-year all-cause mortality. Diabetologia 1995;38(3):318-25.

8. Wild SH, Smith FB, Lee AJ, Fowkes FG. Criteria for previously undiagnosed diabetes and risk of mortality: 15-year follow-up of the Edinburgh Artery Study cohort. Diabetic Medicine 2004;22(4):490-6.

9. Smith NL, Barzilay JI, Kronmal R, Lumley T, Enquobahrie D, Psaty BM. New-onset diabetes and risk of all-cause and cardiovascular mortality: the Cardiovascular Health Study. Diabetes Care 2006;29(9):2012-7.

10. Spijkerman AM, Dekker JM, Nijpels G, Jager A, Kostense PJ, van Hinsbergh VW, et al. Impact of diabetes duration and cardiovascular risk factors on mortality in type 2 diabetes: the Hoorn Study. European Journal of Clinical Investigation 2002;32(12):924-30.

11. Fox CS, Sullivan L, D'Agostino RB, Sr., Wilson PW, Framingham Heart S. The significant effect of diabetes duration on coronary heart disease mortality: the Framingham Heart Study. Diabetes Care 2004;27(3):704-8.

12. Morris AD, Boyle DI, MacAlpine R, Emslie-Smith A, Jung RT, Newton RW, et al. The diabetes audit and research in Tayside Scotland (DARTS) study: electronic record linkage to create a diabetes register. DARTS/MEMO Collaboration. $\mathrm{Br} \mathrm{Med} \mathrm{J}$ 1997;315(7107):524-8.

13. World Health Organization. Manual of the International Statistical Classification of Diseases, Injuries and Causes of Death. Geneva, 1978.

14. World Health Organization. International Statistical Classification of Diseases and Related Health Problems. Geneva: World Health Organization, 1994. 
15. Information and Statistics Division Scotland. Inpatient, day case and outpatient activity. Accessed online 06/10/2009. http://www.isdscotland.org/isd/4159.html

16. Carstairs V, Morris R. Deprivation and health in Scotland. Health Bulletin 1990;48(4):162-75.

17. Evans JM, Newton RW, Ruta DA, MacDonald TM, Morris AD. Socio-economic status, obesity and prevalence of Type 1 and Type 2 diabetes mellitus. Diabetic Medicine: 2000;17478-80.

18. Romeri E, Baker A, Griffiths C. Mortality by deprivation and cause of death in England and Wales, 1999-2003. Health Statistics Quarterly / Office for National Statistics 2006:19-34.

19. Roper NA, Bilous RW, Kelly WF, Unwin NC, Connolly VM. Excess mortality in a population with diabetes and the impact of material deprivation: longitudinal, population-based study. Br Med J 2001; 322:1389-1393.

20. Gigerenzer G, Edwards A. Simple tools for understanding risk: from innumeracy to insight. Br Med J 2003; 327:741-744.

21. Hu G. The DECODE Study Group. Gender difference in all-cause and cardiovascular mortality related to hyperglycaemia and newly-diagnosed diabetes. Diabetologia 2003; 46:608-617.

22. Huxley R, Barzi F, Woodward M. Excess risk of fatal coronary heart disease associated with diabetes in men and women: meta-analysis of 37 prospective cohort studies. BMJ (Clinical Research Ed) 2006;332(7533):73-8.

23. Kanaya AM, Grady D, Barrett-Connor E. Explaining the sex difference in coronary heart disease mortality among patients with type 2 diabetes mellitus: a meta-analysis. Arch Int Med 2002; 162:1737-1745.

24. Harris MI, Klein R, Welborn TA, Knuiman MW. Onset of NIDDM occurs at least 4-7 yr before clinical diagnosis. Diabetes Care 1992; 15:815-819.

25. Guzder RN, Gatling W, Mullee MA, Byrne CD. Early mortality from the time of diagnosis of Type 2 diabetes: a 5-year prospective cohort study with a local age- and sex-matched comparison cohort. Diabetic Medicine 2007;24:1164-7. 